\title{
Sociedad Chilena de Pediatría, período 2007-2008
}

\author{
LIDYA TELLERÍAS C. ${ }^{1}$ \\ 1. Genetista, Hospital San Juan de Dios.
}

Ayúdame a decir la verdad delante de los fuertes, y a no decir mentiras para ganar el aplauso de los débiles. Si me das fortuna, no me quites la razón. Si me das éxito, no me quites la humildad. Si me das la humildad, no me quites la dignidad....

No me dejes caer en el orgullo si triunfo, ni en la desesperación, si fracaso.

Más bien recuérdame, que el fracaso es la experiencia que precede al triunfo.

Gandhi

La Sociedad Chilena de Pediatría, prestigiosa institución que nace el año 1922 gracias al decidido apoyo de distinguidos pediatras, ha cumplido con sus objetivos estatutarios; el primero de ellos señala "Contribuir a elevar el nivel científico y técnico de los profesionales vinculados a la Pediatría, a través de cursos y congresos"; cumpliendo con este punto, se realizó un gran $48^{\circ}$ Congreso en la ciudad de Viña del Mar, con aproximados 900 asistentes; en otro de los puntos se señala, "la difusión de los trabajos científicos a través de una Revista de publicación periódica u otros medios de información", por lo que me permito en esta oportunidad y en esta editorial entregarles una cuenta resumida del Directorio período 2007-2008, enfocando en forma particular al importante trabajo realizado por el Co- mité Editorial de la Revista Chilena de Pediatria, encabezado por su Director-Editor Dr. Francisco Cano Sch., el Comité Editorial a cargo de los Drs. Francisca Ugarte P., Paul Harris, Eduardo Chavez C., Luisa Schonhaut B., Patricio Varela, los Asesores Editoriales Drs. Gastón Duffau T., Cristián García B., Aníbal Espinoza G., Dimitri Parra R., Ximena Cerda, y la permanente participación del Editor Emérito Dr. Carlos Toro.

\section{Cuenta Resumida Directorio 2007-2008}

Se realizaron cursos dirigidos a diferentes profesionales de la salud que atienden niños y adolescentes y a la comunidad en general; más de 100 cursos por año a través de nuestro largo país. Se legalizaron los Estatutos de la Sociedad en diciembre 2007.

En el mes de agosto del 2007 y del 2008, en el marco de los aniversarios de la Sociedad, se organizaron concursos de pintura y fotografía, con gran convocatoria, evidenciando las virtudes de los concursantes, y los grandes dones de los ganadores.

Seguimos trabajando en la prolongación de la licencia postnatal a 6 meses, por lo que asistimos al Senado invitados por el Senador Mariano Ruiz Esquide y la Diputada Sra Carolina Goic, para entregarles una visión técnica con fundamentos médicos, sociales y económicos. Mantuvimos una activa participación en

Correspondencia a:

Lidya Tellerías C.

E-mail: Itellerias@yahoo.com 
ASOCIMED (Asociación de Sociedades Científicas Medicas), Conacem, Minsal, y en la formación de la Agencia Acreditadora de Especialidades Médicas Apice.

Se formaron 2 nuevos Comités, el de Medios y Comunicación, a cargo de Dra. Valeria Rojas y el Comité de Becados, cuya primera presidenta es la Dra. M ${ }^{a}$ Clara Arteaga.

Para dar a conocer nuestra noble institución y posicionarla en la sociedad chilena, especialmente en temas relacionados con los niños y adolescentes, se contrató a una importante empresa de relaciones públicas, que ha iniciado un lento pero fructífero trabajo.

Una de las grandes fortalezas de la Sociedad son sus socios, por lo que se buscaron estrategias para encantar a potenciales socios e reincorporar a aquellos que se habían alejado. Realizamos visitas a diferentes hospitales en santiago, fuimos a regiones, tanto como para apreciar las diferentes realidades, así como para compartir inquietudes y conocimientos. Creemos fundamental la activa y permanente participación de las filiales, por lo cual se ha diseñando una estrategia de apoyo y estímulo que se hará una realidad en los próximos años.

Invitamos a los becados a incorporarse como socios, ellos, nuestros futuros pares y colegas, ellos tienen la vitalidad y serán la semilla que rendirá frutos en un futuro inmediato. Su entusiasmo fue evidente en el simposio de mitos que organizaron en el congreso de Viña, con una espléndida asistencia, y de una alta calidad académica.

Se contrató nuevo personal administrativo, dedicado en forma exclusiva a los socios, y en medio de estas diversas estrategias ingresaron 266 nuevos socios el 2007, y 210 el año 2008. El total de socios actualmente es 1978, lo que nos posiciona como la Sociedad Científica más numerosa del país, lo que significa una gran responsabilidad, de mantenernos unidos, ya que la unión es la que nos da esta gran fortaleza, cada uno, cada rama, comité, filial es un eslabón que forma esta gran cadena llamada SOCHIPE.

Un punto especial para el trabajo realizado por Equipo Editorial de la Revista Chilena de Pediatría. Se digitalizó la Revista desde el primer número el año 1930, con gran esfuerzo y demanda de tiempo, presentando actualmente en el sitio web de SciELO todos los artículos publicados desde el primer número, lo que nos ha permitido mostrar el trabajo científico de nuestra Sociedad en una gran vitrina que atrae miradas desde muchos lugares del mundo, posicionándose en el primer lugar de visitas en este sitio web. Se cambió el formato de la tapa, de acuerdo a reglamentación internacional, se participó activamente en la selección de los trabajos para premio en el Congreso en Viña. Se formó una Comisión para la selección de los Proyectos de Investigación Sochipe, a cargo del Dr. Paul Harris, a quien agradezco y felicito por su abnegada, excelente y objetiva labor.

Un punto especialmente relevante es haber obtenido el Proyecto Conicyt 2009 "Revista Chilena de Pediatría: de las publicaciones en papel a un proceso editorial on-line basado en Open Journal System", lo que nos permitirá por primera vez en el país ofrecer a los investigadores y autores de trabajos científicos, un moderno sistema de presentación electrónica de sus artículos, con todo el proceso editorial a nivel de una plataforma en línea.

Todo este trabajo fue realizado gracias a la valiosa colaboración del Directorio de Sochipe, quienes me apoyaron incondicionalmente durante todo mi período fortaleciendo la gestión de esta Presidencia con sus valiosos consejos, su gran iniciativa, notable capacidad de trabajo, y en especial, su inmensa calidad humana. Es el momento de darles las gracias a ellos, a todo el equipo administrativo, a las entusiastas empresas y muchos anónimos colaboradores que comparten nuestro ideal.

A todos quienes colaboraron, colaboran y colaborarán con esta prestigiosa institución ¡muchas gracias!, deseando para el nuevo Directorio, presidido por el Dr Oscar Herrera el mayor de los éxitos.

Gracias a cada uno por los momentos compartidos.

Un abrazo y... hasta siempre. 